\title{
Patentes y Función Publica Universitaria en Europa: Mitos y Realidades*
}

Ana Urraca Ruiz

Universidade Federal Fluminense (UFF)

Recebido: 2/7/2004 Aprovado: 27/9/2005

\section{RESUMO}

Desde a implementação da Ata Bayh-Dole nos Estados Unidos no início da década dos oitenta, quando as universidades adquiriram plena independência para explorar privadamente os resultados das suas pesquisas, está-se assistindo a um processo de reformulação do papel da função pública das universidades no mundo. A possibilidade de que essa reformulação significasse o abandono de certas funçôes tradicionais da universidade suscitou o debate entre os detratores e os defensores do novo modelo. Utilizando dados da European Patent Office entre 1978 e 2002, este trabalho pretende avaliar em que medida as universidades européias estão registrando também mudanças na sua função pública, tanto pela influência da regulamentação americana quanto pela aparição de novos elementos que modificaram o Sistema Nacional de Inovação, como são o surgimento de novas ciências aplicadas (microbiologia), a necessidade de obter financiamento para o desenvolvimento da pesquisa universitária ou o fortalecimento das relações universidade-empresa.

Agradesco a los revisores anónimos por comentarios y sugestiones. Este trabajo es parte de un proyecto de investigación financiado por el Ministerio de Educación, Cultura y Deportes de España que lleva por título "Análisis y comparación de las patentes universitarias españolas como indicador de resultados del esfuerzo investigador" y que fue desarrollado en el 2003. 
Palavras-Chave | Universidade; Patentes; Europa; Relações Universidade-Empresa; Bens Públicos

Código JEL | O34

\section{ABSTRACT}

Since the beginning of the eighties, a new view for universities has emerged as a consequence of, mainly, four facts: (i) the new model of neo-regulation for universities based on a full independence to appropriate the benefits of their research efforts; (ii) the coming out of new applied sciences, as microbiology; (iii) the enforcement of university-company relationships; and (iii) the need to explore new possibilities to finance public research. Under this scenario, some traditional roles of University as producer and diffuser of scientific and technical knowledge would be losing importance while another would begin to take place: the commercialization and exploration of public research results. Using data from European Patent Office between 1978 and 2002, this paper aims to evaluate if those changes have really happened in European universities. The results confirm, as in the American case, a strong increase of the university patenting activity in Europe. Nevertheless, this activity is still very small and residual and it is too soon to perceive any perverse effect on the traditional university public function as a whole.

KeYwords | University; Patents; Europe; University-firms Relationships; Public Goods

JEL CODE $\mid$ O34 


\section{Introducción}

La Universidad representa, dentro de los Sistemas Nacionales de Innovación, un importante agente en la producción, formación y difusión de conocimiento científico y técnico (CCT). Desde inicios de la década de los ochenta, la función de las universidades se ha ido alterando y ha asumido un nuevo papel: el de comercialización de innovaciones. El Acta "Bayh Dole" de 1980 supuso una ruptura del modelo tradicional de regulación de la función pública universitaria permitiendo por primera vez, en los Estados Unidos, y sin precedentes históricos en ningún otro país del mundo, que las universidades pudieran apropiarse de los derechos de explotación, mediante licencias, de los resultados de sus investigaciones, incluso si éstas fueron financiadas con fondos federales. En 1984, se eliminaron las pocas restricciones impuestas por el Acta "Bayh Dole" sobre el tipo de inventos que podían ser patentados, otorgándolas plena libertad para cobrar royalties sobre patentes o de asignarlas a terceros si así lo deseaban.

Este nuevo modelo de regulación ha sido fuertemente reivindicado en Europa por los defensores de una mayor apertura de las universidades a la sociedad, pero también duramente contestado por los defensores de la función pública universitaria, lo que se conoce como el dilema "publicar o patentar". Los efectos del Acta Bayh Dole y de otros factores sobre ese cambio de papel, como el surgimiento de las relaciones universidad-empresa y de nuevas ciencias aplicadas o la necesidad de buscar nuevas fuentes de financiación de la investigación universitaria, han sido ampliamente estudiados en los Estados Unidos. En Europa, existen pocos trabajos aplicados, tanto porque no está tan clara la ruptura del modelo legal que regula los derechos de propiedad de las universidades como por la mayor resistencia de las universidades europeas a abandonar su tradicional función pública, siendo relegada la cuestión al debate teórico entre "publicar o patentar". En este sentido, este trabajo tiene como objetivo examinar la evolución de la actividad patentadora de las universidades europeas a partir de la base de datos de la European Patent Office entre 1978 y 2002 y para un total de 13 países, a fin de determinar si, verdaderamente, se puede hablar de un cambio en la función pública de la Universidad como proveedora y difusora de conocimiento científico y técnico ante los nuevos cambios dentro de los Sistemas Nacionales de Innovación que se suscitaron desde la década de los ochenta. 


\section{La "función pública" de la Universidad en la innovación tecnológica}

El papel de la Universidad como productora de CCT está asociado a su concepción como centro de reflexión sobre los fenómenos naturales y sociales que son preocupación intrínseca del ser humano. La Universidad representa así, el principal agente capaz de desarrollar "conocimiento por el conocimiento". Este papel tradicional asignado a las universidades hizo que, para algunos, fuesen concebidas como "torre de cristal", donde los científicos trabajaban aislados de la realidad y cuyos objetivos y metas de investigación no deberían responder, o en muy escasa medida, a las necesidades (demandas) económicas y sociales.

Pero también, por otro lado, la producción científica universitaria representa un papel clave en el sistema de innovación por sus fuertes impactos sobre el desarrollo tecnológico y la productividad industrial, dados los fuertes vínculos entre Ciencia y Tecnología. Algunos hechos como los importantes avances científicos registrados a lo largo del siglo XX, el surgimiento de nuevas ciencias de carácter aplicado (ingenierías, robótica, biotecnología) y el crecimiento de las relaciones Universidad-Empresa, han ido llevado a la Universidad a enfocar de forma más "objetiva” su labor investigadora, orientando parte de sus tareas a atender demandas específicas económicas y sociales. La Universidad se convierte así no sólo en un agente capaz de dar soluciones a problemas teóricos y abstractos, sino también, capaz de resolver problemas específicos y aplicados.

Los efectos de investigación universitaria sobre el desarrollo industrial han sido constatados en numerosos trabajos. Un trabajo clásico fue el de Gibbons y Johnston (1974) quienes comprobaron que más de un tercio (36 por ciento) de las unidades de información fuera de las empresas, consideradas como científicas, contribuyeron a la resolución de sus problemas técnicos. A pesar de que en otros trabajos ${ }^{2}$ esta importancia parecia menor, encuestas más recientes parecen corroborarlos. De acuerdo con la Carnegie Mellon Survey de 1994, Cohen et al., (1998) señalaron que:

2 Klevorick et al., (1995) revelaron que la importancia relativa de los laboratorios universitarios como fuente de la oportunidad tecnológica de las empresas era relativamente baja (sólo para 9 industrias obtuvo una puntuación mayor a 5 , todas ellas relativas a campos de la salud y de la agricultura). 
(i) en dos tercios de las industrias manufactureras, la investigación universitaria muestra al menos un campo de conocimiento "moderadamente importante"; ${ }^{3}$

(ii) los laboratorios industriales utilizan técnicas de investigación e instrumentación desarrollada en Universidades;

(iii) la Universidad contribuye a la concepción de nuevas ideas para proyectos industriales de I+D y en las resolución de problemas y ejecución de proyectos existentes y representa una importante fuente de información extramuros como compradora, como usuaria y, especialmente, como competidora; $y$,

(iv) aunque la investigación académica apenas tiene un papel central en pocos sectores, se presenta de gran utilidad para un gran número de sectores por sus efectos expansivos.

El cada vez mayor acercamiento de la Universidad a las demandas de las empresas y la necesidad de introducir vías alternativas de financiación a la investigación universitaria propiciaron la reforma legislativa en los Estados Unidos que supuso el Acta "Bayh Dole". Los efectos previstos de tales medidas sobre la producción de CCT en Universidades por parte de los defensores de la función pública de la investigación académica son (Cohen et al., 1998):

(i) la puesta en compromiso de la norma de mantener abierta la ciencia valorada por los investigadores como un fin en sí mismo;

(ii) cambios previstos en el balance de los esfuerzos investigadores universitarios y de sus resultados en favor de un mayor peso de las actividades destinadas a satisfacer las demandas del mercado y de una menor importancia relativa de las actividades científicas de búsqueda que no persiguen un objetivo concreto;

(iii) la indeterminación de la calidad de la investigación académica en la medida en que los métodos de investigación y los resultados son subjetivados a la revisión y crítica profesional;

(iv) la diseminación de los esfuerzos en investigación básica; un aumento de las

3 Equivalente a una nota 3 sobre una máxima de 4. Además, ocho de 24 industrias indicaron que el 20 por ciento de sus proyectos de investigación usaba investigación universitaria. 
restricciones a la difusión para prevenir resultados de dominio público llevará a un incremento de la duplicación de esfuerzos y a una reducción de la probabilidad de que la investigación contribuya a trabajos futuros, impidiendo el avance acumulativo de la ciencia y la ingeniería.

Las conclusiones de los análisis empíricos no parecen confirmar estas previsiones. Cohen et al., (1998) observaron que, a pesar de la aparente proliferación de empresas de capitalización de resultados de la investigación académica (spin-offs), el porcentaje de investigación básica desarrollada en la Universidad no se ha modificado. Mowery et al., (2001) señalan que el Acta "Bayh Dole" ha tenido poco impacto en el contenido de la investigación académica ya que la investigación universitaria americana no es más aplicada, sino más orientada al área biomédica, lo que no la aparta de la investigación fundamental o básica. Lee (1996) indicó que, cada vez más, las prioridades universitarias se han reorientado abandonando la búsqueda de la resolución de problemas de corto plazo en favor de asuntos fundamentales de largo plazo y comprobó que las universidades que orientaban sus investigaciones a fines más aplicados eran las que contaban con menores gastos en $\mathrm{I}+\mathrm{D}$ y niveles de calidad medios o bajos. Esto significa que los centros académicos más prestigiosos dedican más recursos a la investigación básica que a la aplicada. Mansfield y Lee (1996) corroboraron los resultados de Lee (1996) sobre el importante papel de las universidades de nivel medio y bajo para el desarrollo de nuevos procesos y productos en la industria, aunque destacan, por otro lado, que las universidades citadas por las empresas como las que han contribuido de forma más significativa al desarrollo de sus procesos y productos tienden a ser líderes en la generación de nuevo conocimiento fundamental.

La educación y formación de recursos humanos es otro importante papel de la Universidad en la producción de innovaciones. Gibbons y Johnston (1974) identificaron el doble papel formativo de la Universidad tanto en la oferta de fuerza de trabajo cualificada como en la demanda del conocimiento necesario para la resolución de problemas de la empresa. Así, aunque gran parte de los conocimientos de los investigadores en las empresas son adquiridos dentro de la propia empresa, es fácil observar que éstos poseen estudios universitarios al menos de primer nivel. 
La formación de investigadores en la Universidad tiene ciertos efectos encadenados, puesto que la principal fuente de información utilizada en los procesos de búsqueda es la propia universidad, ampliando el rango de soluciones para problemas específicos con respecto a quien se formó en la propia industria. Es lo que se denomina tener "conocimiento del conocimiento". El investigador con formación universitaria conoce sus limitaciones y sabe en donde buscar la información que necesita. Este hecho es especialmente importante cuando el proceso de búsqueda en la empresa pretende desarrollar nuevos tipos de productos y pierde relevancia cuanto mayor es el grado de especificidad del problema a ser resuelto.

El fortalecimiento de las relaciones Universidad-Empresa ha reorientado también el papel formador de la Universidad. Algunos ejemplos de esto son los "cursos de extensión", realizados por académicos en universidades, cuyo contenido está fuertemente orientado a la especialización de la formación de acuerdo con la demanda de las empresas. Otros autores señalan que el aumento de la investigación aplicada en la Universidad puede afectar negativamente a la formación de los investigadores en la medida en que lleve a una disminución de la calidad de las tesis doctorales, de la educación y del tiempo destinado a docencia por parte de los académicos.

La tercera función de las Universidades es la transferencia de conocimiento a las empresas, papel que fue tomando mayor importancia a lo largo del siglo XX. Gibbons y Johnston (1974) observaron que la media de edad de la literatura científica usada por las empresas en la resolución de problemas técnicos y en la generación de innovaciones era en torno a 12,2 años con una desviación típica de 9,1 años, y el 36 por ciento de las unidades de información analizadas utilizó literatura científica producida en la década anterior a la innovación. Esto llevó a la conclusión de que, aparentemente, la resolución de problemas confía en la información que se desprende de la investigación científica. Mansfield (1991) estableció que el tiempo medio que transcurre entre el resultado académico relevante y su primera aplicación industrial era alrededor de 7 años, observándose un cierto declive - entre 6 y 7 años - para el periodo 1986-1994 (Mansfield, 1998), lo que puede ser el resultado de un cambio en la dirección de la investigación académica hacia campos más aplicados y de corto plazo. Otros trabajos, menos optimistas, recogidos en Cohen et al., (1998), destacan que el periodo de 
tiempo requerido para observar los efectos de la investigación básica sobre la industria era de 20 años en cuanto que, en la ciencias aplicadas, era sólo de 10.

En su papel de difusoras de conocimiento, las universidades utilizan tradicionalmente, como principales canales de transferencia, las publicaciones en libros, revistas científicas, informes y documentos; la presentación de trabajos en congresos y las relaciones interpersonales (por ejemplo, el empleo directo de científicos como consultores). Gibbons y Johnston, (1974) comprobaron que los principales canales de difusión de conocimiento tecnológico a las empresas era la literatura científica (textos y manuales científicos) y contactos con científicos en conferencias, en las propias universidades, etc. La forma predominante de obtención de CCT fue la lectura de revistas relativas a campos particulares de interés científico (aproximadamente el 30 por ciento). El análisis sobre el patrón de transferencia tecnológica de "persona a persona" llevó a los autores a percibir una cierta barrera al uso de fuentes científicas de este tipo porque inhibía la transferencia de CCT a aplicaciones industriales. Más cuando esta barrera era superada, era un fuerte e importante recurso a utilizar.

Con el fortalecimiento de las relaciones Universidad-Empresa se registró un incremento del apoyo financiero de las empresas a la investigación universitaria. Bajo este escenario, surgieron nuevos canales de transferencia de conocimiento como la subcontratación, la esponsorización o la cooperación. A través de estos nuevos mecanismos, los científicos, aunque juegan un pequeño papel en iniciar una innovación tecnológica, son capaces de contribuir a la resolución de problemas técnicos que emergen del proceso de innovación por su experiencia, familiaridad con el conocimiento y facilidades que manejan. Sin embargo, en la mayor parte de los casos, este tipo de relación contractual se traduce en la concesión de exclusividad de transferencia de los derechos de propiedad intelectual, asistencia a empresas, consorcios, consultoría e intercambio de científicos desde la Universidad a la empresa (Lee, 1996).

La entrada en vigor del Acta "Bayh Dole" modificó también el papel de la Universidad como difusora de CCT. La posibilidad de patentar los resultados de la investigación universitaria ha abierto una fuerte controversia. De un lado, los defensores del Acta consideran que las patentes son una forma altamente transparente de difusión de conocimiento porque, cuanto mayor 
es la protección de la propiedad intelectual, más acelerada es su comercialización. En segundo lugar, porque las patentes representan un importante vínculo entre la investigación pura y la aplicación industrial, por lo que se convierte en una vía de difusión a través de la cual los científicos pueden orientar sus esfuerzos a las necesidades del mercado y no sólo al propio conocimiento (Kuckartz, 1999). En tercer lugar, incluso cuando la investigación universitaria es financiada con fondos públicos, es necesario incurrir en fuertes gastos adicionales de I+D y de otro tipo de gastos antes de que los resultados sean comercializados y estos recursos son más probables de obtener si una empresa cuenta con la licencia exclusiva de realizar este trabajo.

Los detractores del Acta argumentan que las patentes y derechos de propiedad, lejos de ser un vehículo de difusión de CCT, pueden representar un serio obstáculo, especialmente cuando incluyen cláusulas restrictivas a la divulgación de información mediante el establecimiento de contratos.

Bajo todas estas consideraciones, los efectos previstos del Acta Bayh Dole sobre la difusión de CCT se resumen en (Cohen et al., 1998; Mowery et al., 2001):

(i) un estrechamiento de las relaciones Universidad-Empresa: en la medida en que parte de la $\mathrm{I}+\mathrm{D}$ académica puede ser apropiada por las empresas, éstas estarán más dispuestas a incurrir en gastos que garanticen la aplicación de los resultados; ${ }^{4}$

(ii) un aumento del coste de uso de los resultados de investigación en ámbitos académicos y no académicos;

(iii) una limitación a la difusión de resultados y de la contribución de la Universidad al avance técnico industrial, puesto que las patentes bloquean los medios más importantes a través de los cuales la Universidad contribuye al avance técnico. Y, en la medida en que se concentran las vías de difusión

4 En este sentido, se han dado dos posturas en Europa. Por un lado, las empresas más grandes están en contra de la divulgación argumentando inseguridad jurídica, mientras que los científicos y las empresas más pequeñas apoyan la difusión de resultados. Los primeros porque suponen un reconocimiento a su labor y, los segundos, porque lo consideran una forma de valorar el potencial técnico o comercial de la invención. Esta discusión puede consultarse en http://europa.eu.int/comm/research. "La controversia sobre el "plazo de gracia»" en Investigación I+DT Info, o el Workshop report "Towards a common European view of the features of a grace period", Bruselas 14.1.2003. Estas cuestiones han llevado a plantear lo que se denomina "plazo de gracia" siguiendo el ejemplo de otros países (EEUU, Japón y Canadá) donde se pueden publicar o divulgar resultados y solicitar una patente en un plazo máximo de seis meses o un año. Como ejemplo, sirve el caso de EEUU en el que una invención que ya ha sido protegida a través de una patente puede ser utilizada, de forma libre, por otros científicos siempre y cuando no obtengan una aplicación comercial. 
y se imponen nuevas restricciones asociadas a las patentes, ${ }^{5}$ incluso las firmas licenciadas pueden observar una reducción del conocimiento público disponible que las beneficia tanto a ellas cuanto a las demás;

(iv) una reducción de los efectos expansivos del conocimiento, por la tendencia de las empresas a retener la ventaja de propiedad y porque se prevé que deberán transcurrir largos periodos de tiempo entre el momento en que la empresa licenciada recibe la información privilegiada y el momento en que ésta lo extiende a otras firmas;

(v) una reducción de beneficios extendidos a las firmas se deberá traducir en una reducción de beneficios también para el consumidor.

Algunos análisis empíricos han tratado de arrojar alguna luz a esta controversia. El trabajo de Henderson et al., (1998) percibe, para los Estados Unidos, un declive año a año de la importancia y generalidad del papel de la Universidad como difusora de CCT desde los años setenta, lo cual puede ser consecuencia de problemas estadísticos relativos a las bases de datos o a cambios en los patrones de citación de patentes. En conjunto, el incremento de la actividad patentadora de las universidades americanas refleja un aumento del ritmo de transferencia de tecnología al sector privado, lo que ha podido llevar a un aumento del ratio de retorno social de la investigación universitaria. No obstante, lo que debe ser importante no es el ritmo al cual está siendo transferido sino que, efectivamente, lo sea.

Sobre la consideración de las patentes como vehículo de difusión, los trabajos de Cohen et al., (1998) y Mowery et al., (2001), también para los Estados Unidos, advierten que el principal y más efectivo canal de transferencia de conocimiento entre la Universidad y la industria es la publicación. Los canales interpersonales son apenas un complemento de otros canales de conocimiento. La subcontratación, patentes y cooperación se consideran canales menos importantes y no son formas relevantes de transferir tecnología para un gran número de tecnologías. En el caso de la biotecnología, la investigación universitaria

5 Algunas de estas restricciones a la apertura de información estudiadas por Cohen et al., (1998:188-190) son el secreto, retrasos en la publicación de resultados, permiso para fiscalizar y borrar información de artículos sometidos a publicación o la facultad de impedir o restringir el compartir información con otros colegas académicos. No obstante, los autores señalan que estas prácticas se limitan a los casos en que las empresas participan financieramente de los costes de la investigación y no entran en estos casos las firmas abiertas por académicos (spin-offs) que simplemente pretenden capitalizar los resultados de la investigación universitaria. 
y la empresarial crecieron en paralelo, de forma que la orientación comercial puede llegar a romper los compromisos de la academia con la investigación básica y con la disponibilidad libre de la información. Basta señalar que, en las áreas de tecnología y ciencias de la vida (agricultura, química y farmacia), entre un 50 y un 60 por ciento de las empresas financian en alguna medida la investigación universitaria.

El trabajo de Blumenthal et al., (1986) mostró que, aunque las facultades que contaban con financiación industrial para sus investigaciones presentaban retrasos en sus publicaciones, eran más productivas en términos de publicación. Y, Lee (1996), a partir de los resultados de una encuesta a científicos en las Universidades, comprobó que las facultades que apoyan con más fuerza las políticas de transferencia universitaria mediante comercialización de resultados son ingeniería química, ingeniería eléctrica, informática y ciencias de materiales.

En resumen, no parece que el nuevo modelo de regulación haya afectado tampoco de forma dramática al papel de la Universidad como difusora de CCT. La extensión de las relaciones financieras entre Universidad y Empresa parece ser un factor más restrictivo a la difusión de CCT que la posibilidad de patentar resultados de investigación por parte de los académicos. Y, en cualquier caso, en la medida de que las patentes son poco utilizadas por la Universidad como vía de difusión de resultados, los efectos sobre su papel difusor se estima que deben ser, hoy por hoy, también muy pequeños.

Finalmente, bajo el nuevo marco legal y considerando el crecimiento de las relaciones Universidad-Empresa, la Universidad ha ganado un "cuarto papel", el de "comercializadora" o "generadora de invenciones comercializables" (Azagra et al., 2001). Tradicionalmente, la Universidad no tenía facultad alguna de comercializar sus resultados careciendo de la posibilidad de obtener retornos de los resultados de su producción científica. En los Estados Unidos, la Universidad compartía con el Estado los resultados de sus investigaciones, negociando con la agencia federal financiadora los términos del llamado Institutional Patent Agreement, en donde se establecía cómo la Universidad debería patentar o ceder bajo licencia los resultados de su investigación. Con el Acta Bayh Dole, la Universidad adquiere la facultad de comercializar a través de patentes o de licenciar los resultados de sus investigaciones, pudiendo obtener retornos sobre sus esfuerzos en investigación. 
El papel comercializador de la Universidad no se limita únicamente a la posibilidad de patentar. Las relaciones entre Universidad y Empresa han acentuado los lazos entre ambas de forma que son múltiples las formas por las cuales la Universidad consigue explotar sus resultados.

La evidencia empírica muestra que la actividad patentadora de la Universidad no ha dejado de crecer desde los años ochenta, lo cual puede ser observado a través de diferentes indicadores: un crecimiento superior al de la actividad patentadora total y al de los gastos en $\mathrm{I}+\mathrm{D}$ universitarios, especialmente en farmacia, medicina y química; un incremento del número de universidades implicadas, aunque están bastante concentradas y, finalmente, un incremento de los ingresos por la comercialización de los resultados.

Los posibles factores que explican esta tendencia son:

(i) el marco legal: de acuerdo con el trabajo de Mowery et al. (2001), el Acta Bayh-Dole tuvo poco impacto en el aumento de la actividad patentadota y de licencia de las universidades ya que, el crecimiento del número de patentes registrado en determinadas áreas (biomedicina) precedió a la firma del Acta en dos de las tres universidades estudiadas (California y Stanford). En la otra (Columbia), estas actividades se vieron aceleradas. Los autores reconocen que el aumento de patentes y licencias derivados de la investigación fundamental o de las herramientas necesarias para su uso en investigaciones posteriores, puede detener el avance de la ciencia y este hecho merece especial atención. En Europa no se han registrado reformas legales tan drásticas, de forma que la posibilidad de utilizar determinadas formas de apropiación todavía están siendo discutidas;

(ii) el aumento de las relaciones Universidad-Empresa. El interés de las industrias por la investigación académica contribuyó al crecimiento de la financiación industrial de la investigación universitaria y al estrechamiento de las relaciones de cooperación, incluso en actividades docentes, especialmente, en las facultades de ingeniería;

6 Thursby \& Kemp (2002) destacan las siguientes: (i) acuerdos de investigación esponsorizados entre universidad y empresa; (ii) acuerdos de licencia que permiten el uso de la propiedad intelectual de las Universidades por parte de empresas privadas; (iii) pagos por royalties recibidos por las universidades a cambio de usar su propiedad intelectual; (iv) apertura de información por facultad a la administración central de innovaciones potencialmente comercializables (mediante la creación de oficinas universitarias de gestión de patentes); y (v) aplicaciones de patentes por universidades 
(iii) La tendencia creciente a explotar nuevas fuentes de financiación; lo cual incluye la aparición de formas de co-financiación con las empresas además de las patentes. De acuerdo con Cohen et al., (1998) algunas razones han motivado este fenómeno: el aumento de la concurrencia entre universidades por la adquisición de fondos federales que se han visto reducidos en las últimas décadas; el cambio de las actitudes del gobierno hacia las colaboraciones entre universidad y empresa, reorientando la financiación a proyectos conjuntos; el mayor incentivo de las empresas a financiar la investigación académica si pueden obtener beneficios sobre resultados de carácter "intermedio" que ayudan a orientar su I+D; y, el mayor incentivo registrado por parte de las universidades, porque ello les permite aumentar la renta personal de los científicos, decidir cuando investigar y mejorar su reputación académica.

(iv) el crecimiento de la investigación académica en áreas de aplicación industrial significativa, como es el caso de la biotecnología o la informática.

Dada la importancia económica y social de la difusión tecnológica, la principal cuestión que se debate es en qué medida el conocimiento debe o no ser patentable por parte de las universidades, y si lo es, qué tipo de conocimiento debe estar protegido y bajo qué sistema de derechos de propiedad y cual no. Y si la apropiación del conocimiento debe ser suficientemente abierta, la cuestión es determinar quien debería apropiarse del conocimiento producido por las universidades y financiado con fondos públicos.

La comercialización de los resultados de la investigación universitaria pasa en alguna medida por la privatización de ciertos bienes públicos creados con recursos también públicos. Este hecho puede provocar distorsiones en la asignación de recursos a la investigación pública con respecto a la iniciativa privada; la substitución de producción de conocimiento científico por tecnológico; el surgimiento de criterios de eficiencia en el ámbito de lo público; el abandono de la investigación desinteresada y fundamental y el estancamiento científico.

No obstante, los resultados empíricos no parecen ser tan dramáticos. Los contenidos de la investigación académica no han registrado cambios sustanciales. El trabajo de Azagra et al. (2001) comprueba que las patentes universitarias continúan siendo en mayor medida el resultado de proyectos de investigación 
procedentes de fondos públicos más que de la subcontratación, el asesoramiento o la explotación de licencias de patentes, lo que significa que el componente de "investigación” todavía es más importante que el componente de "desarrollo". Por tanto, no necesariamente las patentes deberán otorgar a la investigación un carácter estrictamente aplicado y condenado al estancamiento tecnológico. Y, finalmente, a pesar de su fuerte crecimiento, las patentes son muy poco utilizadas como forma de financiación de la investigación pública siendo, ésta última, financiada eminentemente con recursos públicos. La legitimidad de convertir en privados esfuerzos públicos es una cuestión todavía pendiente de resolver.

\section{La actividad patentadora de las universidades europeas}

El estudio de la actividad patentadora de las universidades europeas fue realizado a partir de la base de patentes de la European Patent Office. La selección de países incluía inicialmente a todos los integrantes de la UE más algunos otros que tuvieran fuerte representatividad sobre el total de patentes depositadas en la EPO. Este criterio permitió incluir países no pertenecientes a la UE como Suiza. En conjunto, se ha trabajado con un total de 13 países para los que se encontró un número relevante de patentes universitarias ${ }^{7}$ (Bélgica, Suiza, Alemania, Dinamarca, España, Finlandia, Francia, Gran Bretaña, Grecia, Irlanda, Italia, Portugal y Holanda), cuya actividad patentadora representa el 49,6 por ciento del total de patentes depositadas en la EPO para el periodo 1978-2002.

El análisis ha diferenciado entre patentes depositadas en conjunto y depositadas en solitario. Ello permite hacer un estudio más particularizado de las cooperaciones universitarias con respecto a los esfuerzos investigadores universitarios realizados en solitario. El total de patentes depositadas en solitario por Universidades europeas, entre 1978 y 2002, fue de 1.787 y depositadas en conjunto 556.

El Gráfico 1 muestra la evolución de las patentes europeas entre 1978 y 2002. Durante los años setenta y ochenta, la producción de patentes universitarias en Europa fue muy baja. El primer salto se dio a inicios de los años ochenta para registrar un fortísimo crecimiento a partir de 1994. No obstante, 7 Las tablas presentan sólo resultados para países con más de 3 patentes, lo que hizo eliminar de la muestra original a
Portugal y a Grecia. 
GRAFICO 1

Evolución de las Patentes en Europa

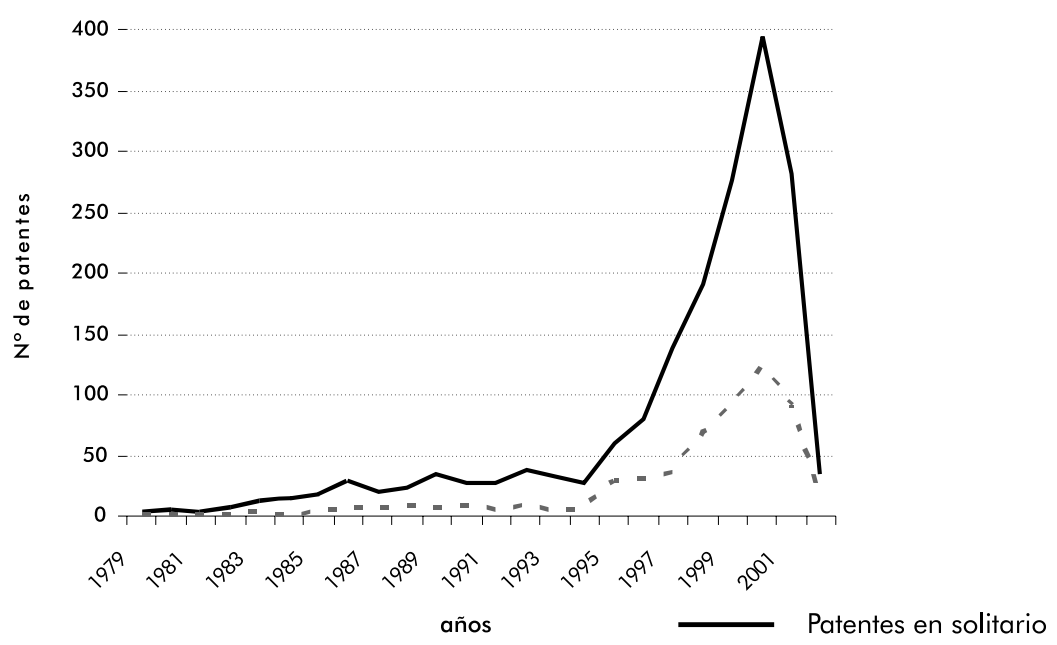

Fuente: EPO (2003) y elaboración propia.

- - - - Patentes en conjunto

desde el año 2000 se ha registrado una caída hasta los niveles de mediados de los noventa. El fuerte pico observado en el año 2001 se debe a problemas metodológicos de la base de datos. El "European Patent Bulletin Information" recoge información entre diciembre de 1978 y diciembre de 2002 y tiene como fecha de elaboración enero de 2003. No obstante, gran cantidad de patentes depositadas a lo largo de 2002 aún no había sido computada en la base de datos en enero de 2003, por lo que los datos de 2002 deben ser considerados apenas como provisionales.

La evolución de las patentes depositadas en solitario por países se presenta en la Tabla 1. Para el total de los países y periodos, se puede observar que el peso de las patentes depositadas en solitario por Universidades sobre el total de patentes depositadas en cada país es muy bajo (apenas un 0,3 por ciento). Este peso es muy inferior al registrado por España, que se configura como el país cuyas universidades tienen un papel más destacado respecto al resto de los agentes. Junto a España, muestran pesos superiores a la media Bélgica, Gran Bretaña, Irlanda y Holanda.

El análisis temporal muestra una evolución creciente de la actividad patentadora de las universidades en Europa (Tabla 1). De apenas 20 patentes 
registradas entre 1978 y 1982 se ha pasado a registrar 1.175 entre 1998 y 2002. No obstante, el salto registrado en la producción de patentes en solitario no se registró simultáneamente en todos los países. Así, en Francia y Gran Bretaña, las universidades comenzaron a manifestar su actividad patentadora a inicios de los ochenta; en España e Italia, a finales de los ochenta; en Bélgica, Alemania, Finlandia y Holanda a mediados de los noventa y en Suiza e Irlanda a finales de los noventa. Y, salvo en el caso de Finlandia, las patentes universitarias depositadas en solitario registraron un fuerte crecimiento entre los periodos 1993-1997 y 1998-2002 en todos los países. Las nuevas tendencias neoreguladoras iniciadas con el Acta "Bayh Dole" se dejaron notar en Europa con un cierto atraso. Un carácter más proteccionista y defensor de la Universidad pública como salvaguarda de la producción científica y la resistencia de las universidades a reorientar parte de su investigaciones hacia de resolución de problemas más aplicados y específicos, explican este fenómeno. Pero este atraso no significa que el cambio en la actitud patentadora de las universidades europeas no haya sido intenso. Observando la segunda parte de la Tabla 1 se puede comprobar que el peso de las patentes universitarias sobre el total de patentes es cada vez mayor, lo que significa que el crecimiento de las patentes universitarias es más acelerado que el de otros agentes o que el del país como un todo. Este crecimiento acelerado es especialmente importante en el caso de Gran Bretaña, donde las patentes universitarias, hasta 1997 , apenas representaban un $1 \%$ del total de patentes, pasando a representar un 3\% en el periodo 1998-2002.

Los indicadores escogidos para caracterizar la actividad patentadora de las universidades europeas por países son el ratio entre cooperaciones y depósitos en solitario, el ratio entre gastos en $\mathrm{I}+\mathrm{D}$ privados y universitarios y el grado de internacionalización (Tabla 2). El balance entre patentes en cooperación sobre patentes en solitario es igual a 100 cuando, para cada país, las universidades registran el mismo número de patentes en conjunto que en solitario. Este indicador muestra que las universidades irlandesas son eminentemente cooperadoras, depositando en conjunto casi el doble de lo que depositan en solitario (185,7). En el resto de los países el índice es siempre inferior a 100, presentando balances más equilibrados Francia, España y Bélgica (68,4, 64,4 y 55,1 por ciento respectivamente). Los países cuyas Universidades presentan balances más bajos son Italia (29,3 por ciento), Alemania (20,8 por ciento) y Gran Bretaña (18,4 por ciento). 
TABLA 1

Patentes depositadas en solitario por universidades europeas

\begin{tabular}{|c|c|c|c|c|c|c|c|c|c|c|c|c|}
\hline \multicolumn{7}{|c|}{ Patentes universitarias depositadas en solitario } & \multicolumn{6}{|c|}{ Pesos sobre total patentes depositadas (\%) } \\
\hline & $78-82$ & $83-87$ & $88-92$ & 93-97 & $98-02$ & Total & 78-82 & $83-87$ & $88-92$ & 93-97 & 98-02 & Total \\
\hline Bélgica & & 5 & 3 & 25 & 94 & 127 & 0,0 & 0,2 & 0,1 & 0,5 & 1,8 & 0,8 \\
\hline Suiza & & 1 & 1 & 1 & 30 & 33 & 0,0 & 0,0 & 0,0 & 0,0 & 0,3 & 0,1 \\
\hline Alemania & & 1 & 4 & 43 & 154 & 202 & 0,0 & 0,0 & 0,0 & 0,1 & 0,2 & 0,1 \\
\hline España & & & 10 & 35 & 42 & 87 & 0,0 & 0,0 & 0,8 & 1,7 & 1,7 & 1,4 \\
\hline Finlandia & & & & 6 & 5 & 11 & 0,0 & 0,0 & 0,0 & 0,2 & 0,1 & 0,1 \\
\hline Francia & 2 & 11 & 14 & 25 & 81 & 133 & 0,0 & 0,1 & 0,1 & 0,1 & 0,3 & 0,1 \\
\hline G.Bretaña & 17 & 73 & 91 & 163 & 571 & 915 & 0,2 & 0,5 & 0,5 & 0,8 & 2,8 & 1,1 \\
\hline Irlanda & & & 2 & & 12 & 14 & 0,0 & 0,0 & 0,6 & 0,0 & 1,5 & 0,7 \\
\hline Italia & & & 19 & 20 & 60 & 99 & 0,0 & 0,0 & 0,2 & 0,2 & 0,4 & 0,2 \\
\hline Holanda & 1 & 5 & 9 & 20 & 126 & 161 & 0,0 & 0,1 & 0,1 & 0,2 & 1,2 & 0,5 \\
\hline Total & 20 & 96 & 153 & 338 & 1175 & 1782 & 0,0 & 0,1 & 0,1 & 0,2 & 0,7 & 0,3 \\
\hline
\end{tabular}

Fuente: EPO (2003) y elaboración propia.

El ratio de los gastos en $\mathrm{I}+\mathrm{D}$ de empresas y el de las universidades revela la importancia relativa de los esfuerzos privados sobre los públicos. Tradicionalmente, este ratio es más elevado en los países tecnológicamente más avanzados (Alemania, Gran Bretaña o Francia), ya que en estos países la actividad tecnológica está liderada por empresas. Aparecen como significativos los elevados ratios, en téminos relativos, de países con un nivel tecnológico medio bajo (catch-up) como son los casos de Finlandia o Irlanda. Italia y España muestran los ratios más bajos, lo que significa un fuerte equiibrio entre los esfuerzos públicos y privados a la innovación.

El grado de internacionalización (última columna de la Tabla 2) indica que, con carácter general, las universidades europeas son poco internacionalizadas (8,67 por ciento). La mayor parte de las universidades europeas utilizan 
TABLA 2

Caracterización de las patentes depositadas en solitario por universidades europeas

\begin{tabular}{|c|c|c|c|c|c|c|}
\hline & \multicolumn{3}{|c|}{$\mathrm{HHI}$ - Concentración por campo técnico } & \multirow[b]{2}{*}{$\begin{array}{l}\text { P. Cooperación/ } \\
\text { P. Solitario (\%) }\end{array}$} & \multirow[b]{2}{*}{$\begin{array}{l}\text { GID empresa/ } \\
\text { GID univ. } 1(\%)\end{array}$} & \multirow[b]{2}{*}{$\begin{array}{c}\text { Grado } \\
\text { Internacional }^{2}\end{array}$} \\
\hline & $\begin{array}{l}\text { P. universitarias } \\
\text { En solitario }\end{array}$ & $\begin{array}{l}\text { P. universitarias } \\
\text { en cooperación }\end{array}$ & $\begin{array}{l}\text { Patentes } \\
\text { Totales }\end{array}$ & & & \\
\hline Bélgica & 0,237 & 0,230 & 0,137 & 0,55 & 3,0 & 11,02 \\
\hline Suiza & 0,304 & 0,523 & 0,093 & 0,48 & - & 39,39 \\
\hline Alemania & 0,232 & 0,204 & 0,100 & 0,21 & 4,3 & 7,43 \\
\hline España & 0,182 & 0,268 & 0,090 & 0,64 & 1,7 & 6,90 \\
\hline Finlandia & 0,603 & - & 0,149 & 0,00 & 3,5 & 9,09 \\
\hline Francia & 0,253 & 0,267 & 0,101 & 0,68 & 3,7 & 6,77 \\
\hline G.Bretaña & 0,218 & 0,234 & 0,114 & 0,18 & 3,4 & 8,74 \\
\hline Irlanda & 0,286 & 0,429 & 0,119 & 1,86 & 3,4 & 28,57 \\
\hline Italia & 0,337 & 0,322 & 0,088 & 0,29 & 1,5 & 3,03 \\
\hline Holanda & 0,286 & 0,281 & 0,125 & 0,37 & 2,2 & 6,21 \\
\hline Total & - & - & - & 0,31 & $3,1^{*}$ & 8,67 \\
\hline
\end{tabular}

Fuente: EPO (2003) y elaboración propia.

* media UE.

1 Cociente entre los Gastos en I+D realizados por empresas como porcentaje del PIB y los Gastos en I+D realizados por centros de enseñanza superior como porcentaje del PIB. Fuente: MCYT, 2002.

2 Peso das patentes universitarias (solitario) internacionalizadas sobre el total de patentes universitarias (solitario). Se considera que una patente es internacionalizada cuando al menos uno de sus inventores tiene la residencia en un país diferente al país de residencia de la universidad que deposita la patente.

únicamente inventores residentes en el mismo país de la universidad. Las universidades más internacionalizadas son las suizas, con un grado de internacionalización de casi el 40 por ciento, y las irlandesas, con un grado de internacionalización del 28,57 por ciento. Las menos internacionalizadas son las italianas con un grado de internacionalización de apenas un 3 por ciento.

La distribución de patentes depositadas en solitario por campo técnico es extremamente similar entre países (Tabla 3). El índice HHI indica que, para todos los países, la concentración de las patentes depositadas por las universidades es 


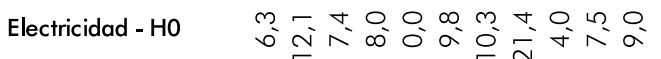

$\begin{array}{llllllllllll}\text { Ciencia Nuclear-G2 } & 0 & 0 & 0 & 0 & 0 & 0 & 0 & 0 & 0 & 0 & 0 \\ 0 & 0 & 0 & 0 & 0 & 0 & 0 & 0 & 0 & 0 & 0 & 0\end{array}$

Instrumentos-GO+G1 $m \sim \infty+m m b a \sim a$ กั่

Armas y

Explosivos - F4

lluminación y

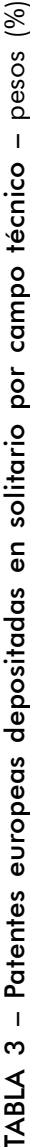

Calefacción - F2

Ingenieria - F 1

Motores y

Bombas- FO

Perforación y

Minería-E 2

Construcción - EO

Papel - D2

Textil y materiales

flexibles - DO

Metalurgia -

$\mathrm{C} 2+\mathrm{C} 3$

Química y

Farmacia- $\mathrm{CO}+\mathrm{Cl}$

Trans porte-B 6

Impresión - B4

Conformación

B2+B3

Separación y Mezclas - BO

Salud $y$

deporte - A6

Articulos uso personal - A4

Alimentos y

Tabaco - A2

Agricultura-AO

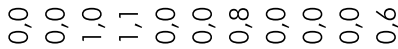

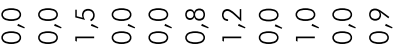

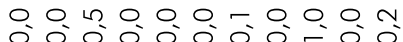
$\begin{array}{llllllll}0 & 0 & 0 & 0 & 0 & m & n & 0 \\ 0 & 0 & 0 & 0 & 0 & 0 & 0 & 0 \\ 0 & 0 & 0 & 0 & 0\end{array}$


$0+-m \wedge 0 \infty$ o n m

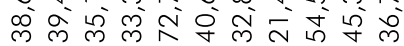

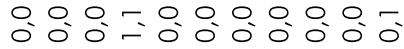
웡 $\forall a$

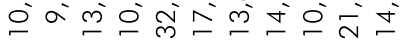

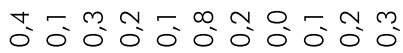
nN ตั่

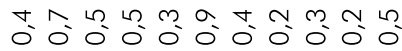

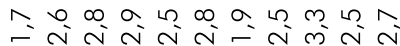

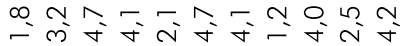

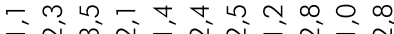

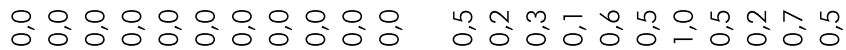

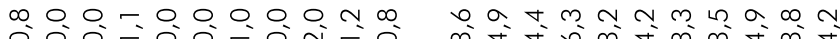

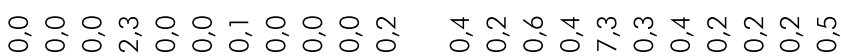
mĩ

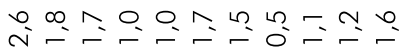

0 n o n mo na

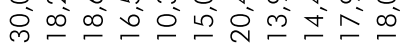

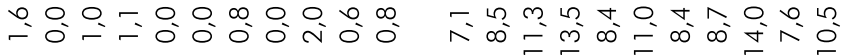
ñ

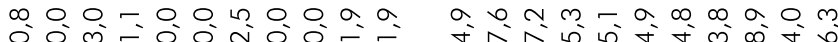
号 d

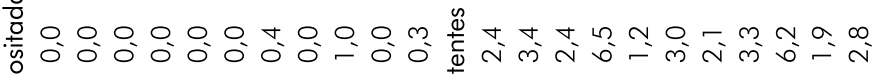

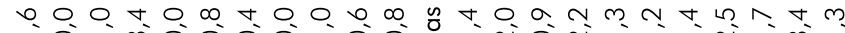
\& = 市

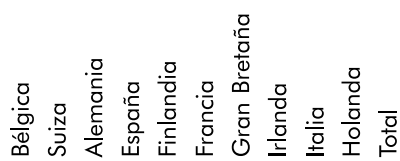

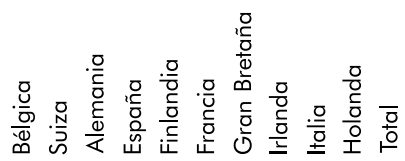


mayor que la concentración de las patentes depositadas por el total de agentes de cada país. Esto significa que las patentes depositadas por otros agentes se distribuyen en mayor proporción en áreas técnicas diferentes de las típicamente universitarias. El país que presenta un mayor índice de concentración, derivado del bajo número de patentes registradas ( 8 en total), es Finlandia $(\mathrm{HHI}=0,603)$ y el de menor concentración, España $(\mathrm{HHI}=0,182)$.

Los campos técnicos en donde las patentes universitarias depositadas en solitario revelan pesos más elevados y por encima de lo registrado para el total de patentes son Química y Farmacia (36,7 por ciento), Instrumentos (21,5 por ciento) y Salud y Deportes (19,2 por ciento). Electricidad, aunque presenta un peso elevado en términos relativos ( 9,0 por ciento) se encuentra por debajo de lo registrado para el total de patentes. Destaca, por otro lado, una actividad patentadora nula, o casi nula, en campos técnicos como Alimentos y Tabaco, Artículos de Uso Personal, Impresión, Transporte, Textil y Materiales Flexibles, Papel, Construcción, Perforación y Minería, Motores y Bombas, Ingeniería, Iluminación y Calefacción, Armas y Explosivos y Ciencia Nuclear.

La similitud de la estructura de las patentes por campos técnicos entre países es extremadamente fuerte con algunas particularidades sobre la tendencia general. Irlanda es el único país en donde las universidades se concentran con mayor intensidad en Instrumentos, por encima de Química y Farmacia; en Suiza, Alemania y Holanda las universidades concentran más intensamente su actividad patentadora en Salud y Deportes (donde está incluida la biotecnología) que en Instrumentos. En algunos países, las universidades enfocan su actividad patentadora con mayor intensidad hacia campos técnicos diferentes de los tres principales. Así, por ejemplo, las españolas se concentran más en Separación y Mezclas que en Salud y Deportes y las irlandesas, que en este campo no desarrollan ninguna actividad, registran una mayor importancia relativa los campos de Agricultura y Metalurgia.

La especialización de la actividad patentadora fue medida a través de la Ventaja Tecnológica Revelada (VTR) en la Tabla 4. La VTR se calcula, para cada país, como el peso de cada campo técnico sobre el total de patentes universitarias dividido entre el peso que ese mismo campo técnico tiene sobre el total de patentes depositadas por el país. La VTR muestra que, con carácter general, las universidades europeas están especializadas en las tres áreas técnicas en donde concentran con 
TOTAL

Electricidad - HO

Ciencia Nuclear-G2

Ciencia Nuclear - G2

Instrumentos -

G0+G1

Armas y Explosivos -

F4

Iluminación y

Calefacción - F2

Ingenieria - F 1

Motores y Bombas-

FO

Perforación y

Minería -E 2

Construcción - E 0

Papel - D2

Textil y materiales

flexibles - D0

Metalurgia $-\mathrm{C} 2+\mathrm{C} 3$

Química y Farmacia-
$\mathrm{C} 0+\mathrm{Cl}$

Transporte-B 6

Impresión-B 4

Conformación B2+B3

Separación y

Mezclas - BO

Salud y deporte - A6

Articulos uso

personal - A4

Alimentos y Tabaco -A2

Agricultura-A0

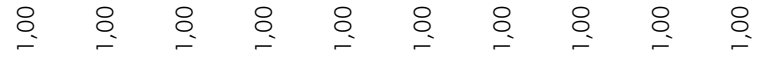

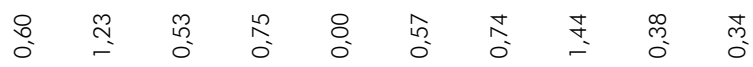

$\begin{array}{llllllllll}0 & 8 & 0 & 0 & 0 & 0 & 0 & 0 & 0 & 0 \\ 0 & 0 & 0 & 0 & 0 & 0 & 0 & 0 & 0 & 0\end{array}$

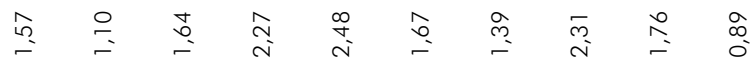

:

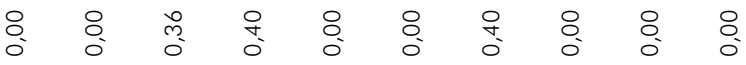

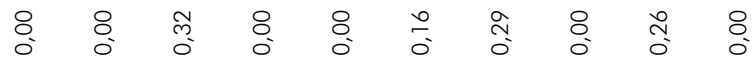

$\begin{array}{llllllllll}0 & 0 & 0 & 0 & 0 & 0 & 0 & 0 & 0 & 0 \\ 0 & 0 & 0 & 0 & 0 & 0 & 0 & 0 & 0 \\ 0\end{array}$

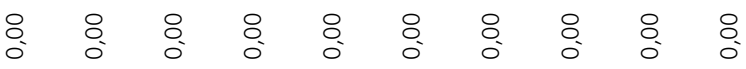

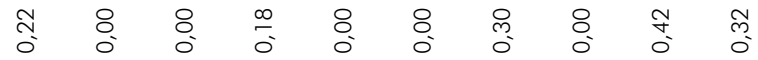

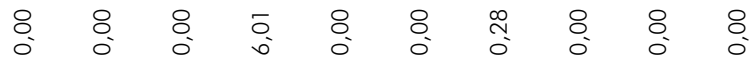

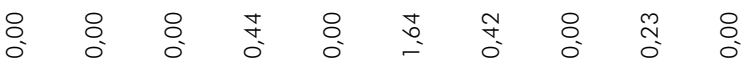

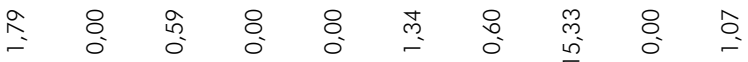

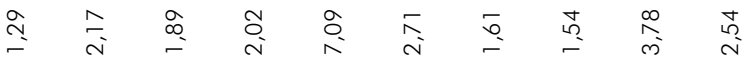

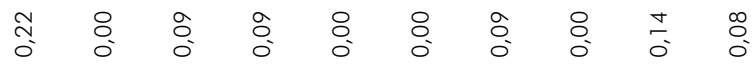

$\begin{array}{llllllllll}0 & 0 & 0 & 0 & 0 & 0 & 0 & 0 & 0 & 0 \\ 0 & 0 & 0 & 0 & 0 & 0 & 0 \\ 0\end{array}$

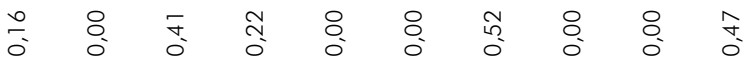

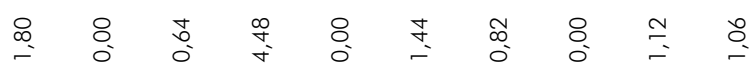

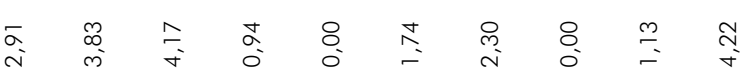

o.

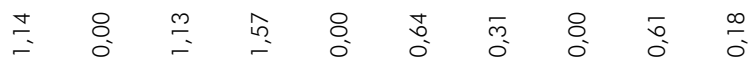






mayor intensidad sus patentes: Química y Farmacia, Instrumentos y Salud y Deporte. Y, a diferencia de lo que se registra en los Estados Unidos, las ingenierías no representan para las universidades europeas un campo técnico de actuación como ciencia de transferencia entre el conocimiento básico y el aplicado.

Sobre estas características generales, algunas particularidades pueden ser destacadas: las universidades belgas son las únicas que no alcanzan niveles de especialización superiores a 1,5 en Química y Farmacia, mostrando especialización en Separación y Mezclas y Metalurgia; en Suiza, Gran Bretaña y Holanda, las universidades no muestran VTR superior a 1,5 en Instrumentos, siendo que se encuentran especializadas apenas en Química y Farmacia y Salud y Deportes; en España, Finlandia, Irlanda e Italia, las universidades no aparecen especializadas en Salud y Deportes. En su lugar, presentan fuertes índices de especialización en campos técnicos que no se corresponden con la concentración de sus esfuerzos. Así, por ejemplo, España se encuentra especializada en Agricultura, Alimentos y Tabaco, Separación y Mezclas y Papel; Irlanda se especializa en Agricultura y Metalurgia; e, Italia se especializa en Agricultura; en Francia, las universidades se especializan, además de los tres campos técnicos mencionados, en Textil y Materiales Flexibles.

Sin embargo, las universidades europeas participan en escasa medida de la formación de competencias en cada uno de sus países por el escaso peso de sus patentes sobre el total de patentes depositadas por cada país. En ningún campo técnico, las patentes depositadas en solitario por universidades para el total de los países, llega a representar el 1 por ciento del total de patentes depositadas (Tabla 5). Dentro de esta tónica general, España es el país que más ayuda a la formación de competencias tecnológicas nacionales en las áreas técnicas en que está especializada en comparación con las aportaciones realizadas por sus homólogas europeas. Así, por ejemplo, España aporta un 3,52 por ciento a la formación de competencias nacionales en Agricultura; con un 6,21 por ciento en Separación y Mezclas; con un 8,33 por ciento en Papel; con un 3,15 por ciento en Instrumentos; y, con un 2,17 por ciento en Alimentos y Tabaco. Junto a España, destaca el papel de las universidades irlandesas en la formación de competencias nacionales en Metalurgia (11,11 por ciento). Con aportaciones entre un 2 y un 3 por ciento se destacan tan sólo los casos de Bélgica y Gran Bretaña en Salud y Deportes. 
TOTAL

Electricidad - HO

Ciencia Nuclear- G2

Instrumentos - G0+G1

Armas y Explosivos - F4

Iluminación y Calefacción F2

Ingenieria - F 1

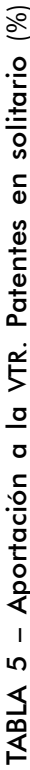

Papel - D2

Textil y materiales

flexibles - DO

Metalurgia - $\mathrm{C} 2+\mathrm{C} 3$

Química y Farmacia-

$\mathrm{CO}+\mathrm{Cl}$

Trans porte-B 6

Impresión - B4

Conformación B2+B3

Separación y Mezclas - BO

Salud y deporte - A6

Articulos uso personal - A4

Alimentos y Tabaco - A2

Agricultura-A0

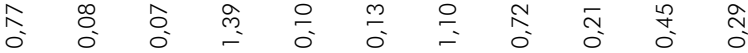

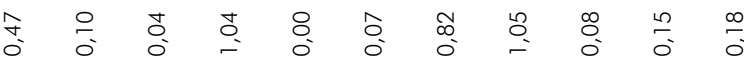

$\begin{array}{lllllllllll}8 & 8 & 8 & 8 & 8 & 8 & 8 & 0 & 8 & 8 & 8 \\ 0 & 0 & 0 & 0 & 0 & 0 & 0 & 1 & 0 & 0 & 0\end{array}$

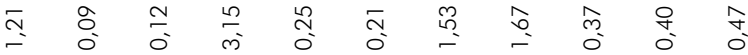

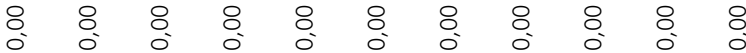

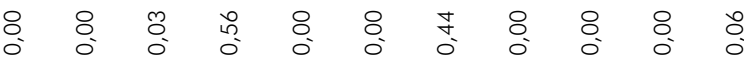

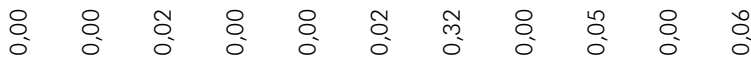

$\begin{array}{lllllllllll}\circ & 8 & 0 & \circ & 8 & 8 & 0 & 8 & 0 & 0 & 0 \\ 0 & 0 & 0 & 0 & 0 & 0 & 0 & 0 & 0 & 0 & 0\end{array}$

$\begin{array}{lllllllllll}8 & 8 & 8 & 8 & 8 & 8 & 8 & 8 & 8 & 8 & 8 \\ 0 & 0 & 0 & 0 & 0 & 0 & 0 & 0 & 0 & 0 & 0\end{array}$

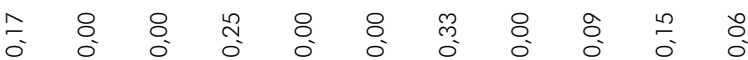

$\begin{array}{lllllllllll}8 & 8 & 8 & m & 8 & 8 & \bar{m} & 8 & 8 & 8 & 0 \\ 0 & 0 & 0 & \infty & 0 & 0 & 0 & 0 & 0 & 0 & 0\end{array}$

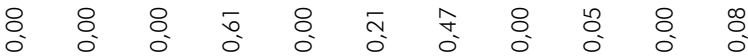

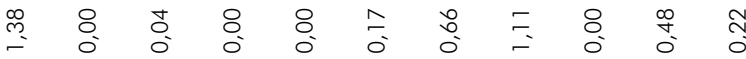

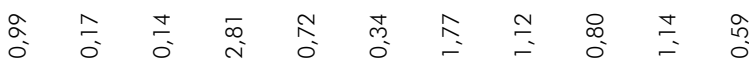

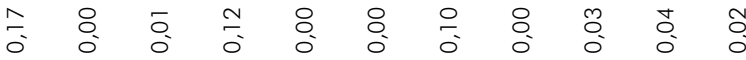

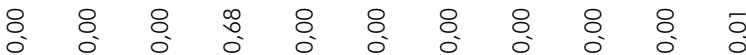

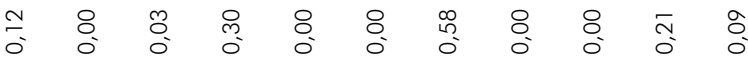

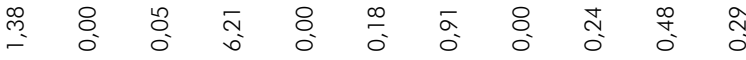

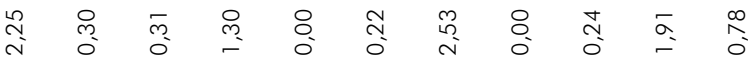



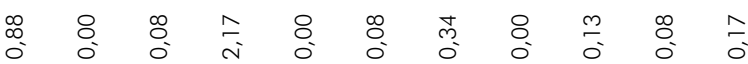

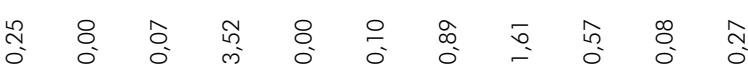

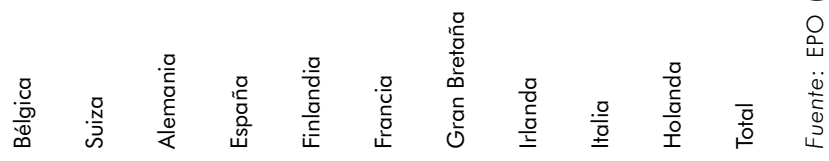


Estos resultados llevan a concluir que las universidades europeas no realizan una importante actividad patentadora en solitario, dentro de sus países, siendo ésta una actividad más propia de empresas. Como en el caso de España, es fácil prever que la transferencia de CCT se realiza de forma más importante a través de otras vías, como publicaciones científicas, siendo esta una medida más apropiada para medir su papel dentro de los sistemas nacionales de innovación como generadoras de innovaciones.

TABLA 6

Evolución de las patentes ${ }^{1}$ en Europa por campo técnico

\begin{tabular}{|c|c|c|c|c|c|c|}
\hline & $78-82$ & $83-87$ & $88-92$ & $93-97$ & $98-02$ & Total \\
\hline Agricultura & 2 & 1 & 3 & 7 & 18 & 31 \\
\hline Alimentos y tabaco & & & 3 & 3 & 8 & 14 \\
\hline Artículos de uso personal & 1 & & & 1 & 3 & 5 \\
\hline Salud y Deporte & 3 & 25 & 25 & 77 & 214 & 344 \\
\hline Separación y Mezclas & & 4 & 4 & 12 & 42 & 62 \\
\hline Conformación & 1 & 2 & 3 & 5 & 23 & 34 \\
\hline Impresión & & & & & 1 & 1 \\
\hline Transporte & & 3 & & 2 & 10 & 15 \\
\hline Química y Farmacia & 3 & 22 & 55 & 149 & 427 & 656 \\
\hline Metalurgia & & 3 & 3 & 3 & 13 & 22 \\
\hline Textil y materiales flexibles & & & 2 & & 8 & 10 \\
\hline Papel & & & & & 3 & 3 \\
\hline Construcción & & 1 & 4 & 1 & 9 & 15 \\
\hline Motores y Bombas & & 1 & & & 2 & 3 \\
\hline Ingeniería & 1 & & 2 & 1 & 12 & 16 \\
\hline Iluminación y Calefacción & & & 1 & 6 & 3 & 10 \\
\hline Instrumentos & 6 & 25 & 37 & 49 & 268 & 385 \\
\hline Electricidad & 3 & 9 & 11 & 23 & 115 & 161 \\
\hline Total general & 20 & 96 & 153 & 339 & 1179 & 1787 \\
\hline
\end{tabular}

Fuente: EPO (2003) y elaboración propia.

1 Depositadas en solitario. 
No es posible concluir, por tanto que, en Europa, las tendencias hacia una nueva regulación sobre apropiación de nuevo CCT hayan llevado a un desplazamiento de la función social de la Universidad hacia una sustitución radical de la investigación básica por aplicada o de los mecanismos tradicionales de difusión por otros más restrictivos. El número de patentes universitarias depositadas en solitario ha crecido enormemente desde inicios de los noventa, pero este crecimiento se ha concentrado en pocas áreas técnicas (Química y Farmacia, Salud y Deporte, Instrumentos y Electricidad -que incluye electrónica) (Tabla 6). Estos campos técnicos se relacionan con disciplinas científicas consideradas como "ciencias básicas" y son los que tradicionalmente concentraban los esfuerzos patentadores de las Universidades, por lo que no parece que se esté registrando una reorientación de la investigación académica más alejada de la ciencia.

\section{Las cooperaciones universitarias}

La interrelación de las universidades con otros agentes, en especial con las empresas, será estudiado a partir de las cooperaciones. Para ello, se han considerado cooperaciones aquellas patentes que son depositadas conjuntamente por una universidad y por un otro agente, bien sea Empresa, Centro Público de Investigación (CPI), Administraciones Públicas, Investigadores Independientes u otra universidad. En los casos en que las patentes eran depositadas por dos universidades de nacionalidad diferente y las dos nacionalidades se correspondían con las del grupo de países considerados, se contabilizaron dos cooperaciones, una para cada país. Esto elevó el número de cooperaciones a 559.

Las cooperaciones universitarias en Europa han evolucionado muy favorablemente a lo largo del periodo considerado. Al igual que las patentes depositadas en solitario, las universidades europeas presentan una tendencia creciente a patentar en conjunto con otros agentes, siendo especialmente acelerada a partir del periodo 1993-1997 (Tabla 7). El país que muestra una mayor tradición en este tipo de relaciones es Gran Bretaña, en cuanto que Suiza o Alemania tan sólo iniciaron este tipo de actividad en los años noventa.

En conjunto, ésta es una actividad más reciente que la de patentar en solitario, lo cual es absolutamente coherente con la orientación de la investigación académica en Europa. Las nuevas tendencias en el avance de la ciencia 
TABLA 7

Patentes depositadas en conjunto por universidades europeas

\begin{tabular}{|c|c|c|c|c|c|c|c|c|c|c|c|c|}
\hline \multicolumn{7}{|c|}{ Patentes universitarias depositadas en conjunto } & \multicolumn{6}{|c|}{ Pesos sobre total patentes depositadas (\%) } \\
\hline & $78-82$ & $83-87$ & $88-92$ & 93-97 & $98-02$ & Total & $78-82$ & $83-87$ & $88-92$ & 93-97 & $98-02$ & Total \\
\hline Bélgica & & 3 & 2 & 12 & 53 & 70 & 0,00 & 0,14 & 0,06 & 0,25 & 1,00 & 0,42 \\
\hline Suiza & & & & 2 & 14 & 16 & 0,00 & 0,00 & 0,00 & 0,02 & 0,14 & 0,04 \\
\hline Alemania & & & & 2 & 40 & 42 & 0,00 & 0,00 & 0,00 & 0,00 & 0,05 & 0,02 \\
\hline España & & & 4 & 13 & 39 & 56 & 0,00 & 0,00 & 0,32 & 0,64 & 1,62 & 0,89 \\
\hline Francia & & 6 & 15 & 19 & 51 & 91 & 0,00 & 0,04 & 0,06 & 0,07 & 0,18 & 0,09 \\
\hline G. Bretaña & 4 & 12 & 17 & 43 & 93 & 169 & 0,05 & 0,08 & 0,09 & 0,21 & 0,45 & 0,20 \\
\hline Irlanda & & & 2 & 3 & 21 & 26 & 0,00 & 0,00 & 0,60 & 0,56 & 2,66 & 1,35 \\
\hline Italia & 1 & 1 & & 3 & 24 & 29 & 0,05 & 0,02 & 0,00 & 0,02 & 0,17 & 0,06 \\
\hline Holanda & & & 2 & 9 & 49 & 60 & 0,00 & 0,00 & 0,02 & 0,10 & 0,47 & 0,17 \\
\hline Total & 5 & 22 & 42 & 106 & 384 & 559 & 0,01 & 0,02 & 0,03 & 0,07 & 0,22 & 0,09 \\
\hline
\end{tabular}

Fuente: EPO (2003) y elaboración propia.

y la necesidad de encontrar aplicaciones al conocimiento científico parecen haber modificado las relaciones de la Universidad con otros agentes, lo que se ha traducido en un aumento de las interrelaciones que mantiene con ellos.

Sin embargo, y a la vista de lo que muestra la segunda parte de la Tabla 7, las cooperaciones son todavía poco relevantes dentro de la actividad patentadora total. Hasta el periodo 1998-2002 las cooperaciones universitarias no representaban ninguna importancia dentro del total de patentes depositadas y, aunque la tendencia es creciente, es enormemente baja (el 0,2 por ciento del total). En países de elevada actividad patentadora, las cooperaciones universitarias, a pesar de haber crecido enormemente, no adquieren importancia cuando se comparan con el total de patentes. Son los casos de Alemania, Suiza o Francia.

Los principales agentes que cooperan con universidades son, en orden de importancia, las empresas y los CPIs y, aunque ambos se reparten los pesos de forma bastante equitativa ( 45,1 y 32,5 por ciento respectivamente), se observa 
una tendencia creciente de la relaciones de cooperación con las empresas desde inicios de los noventa. Le sigue en importancia las cooperaciones entre universidades (14,4 por ciento), cada vez más relevantes desde los años noventa; los inventores independientes (5,04 por ciento), que tuvieron cierta importancia como cooperantes en el pasado, cada vez aparecen como menos importantes; $y$, finalmente, las Administraciones (2,88 por ciento), que aparecen como socios de manera eventual (Tabla 8).

TABLA 8

Evolución de la importancia relativa de los agentes que cooperan con universidades en Europa

\begin{tabular}{lcccccc}
\hline & $78-82$ & $83-87$ & $88-92$ & $93-97$ & $98-02$ & Total \\
& 0,00 & 0,00 & 14,29 & 0,00 & 2,62 & 2,88 \\
Administración & & & & & & \\
Centros Públicos de Investigación & 20,00 & 40,91 & 40,48 & 35,85 & 30,45 & 32,55 \\
Empresas & 60,00 & 40,91 & 38,10 & 40,57 & 47,24 & 45,14 \\
Inventores Independientes & 20,00 & 18,18 & 4,76 & 8,49 & 3,15 & 5,04 \\
Otras Universidades & 0,00 & 0,00 & 2,38 & 15,09 & 16,54 & 14,39 \\
Total Global & 100,00 & 100,00 & 100,00 & 100,00 & 100,00 & 100,00 \\
& & & & & & \\
\hline
\end{tabular}

Fuente: EPO (2003) y elaboración propia.

La importancia relativa de cada agente cooperante varía considerablemente entre países (Tabla 9). Los CPIs son importantes cooperadores de las universidades en Suiza, Francia, España y Bélgica, representando más de la mitad del total de las cooperaciones, sin embargo tienen escasa importancia en Alemania (11,9 por ciento), Gran Bretaña (13,2 por ciento) e Irlanda (3,85 por ciento). En estos tres países, son las empresas las que adquieren un papel destacado como cooperadoras de las universidades representado el 66,7 por ciento del total de cooperaciones en Alemania, el 60,4 por ciento en Gran Bretaña y el 76,9 por ciento en Irlanda. Los índices de concentración confirman que, entre agentes, las cooperaciones universitarias se concentran en Empresas y CPIs. Las universidades que concentran su actividad patentadora entre un menor número 
de socios son las irlandesas $(\mathrm{HHI}=0,61)$ y las suizas $(\mathrm{HHI}=0,57)$. El resto de países muestra HHI superiores, mas próximos, a la media registrada por el conjunto. Sobre esta generalidad destaca el caso de Italia que se presenta como el país que más diversifica sus cooperaciones entre un número mayor de agentes.

TABLA 9

Importancia relativa y concentración de las cooperaciones universitarias europeas por tipo de agente cooperante (1978-2002)

\begin{tabular}{lcccccc}
\hline & \multicolumn{5}{c}{ Pesos sobre el total por país (\%) } \\
& Administración & CPI & Empresas & Inventores & Universidades & HH \\
Bélgica & 2,86 & 50,00 & 25,71 & 5,71 & 15,71 & 0,34 \\
Suiza & 0,00 & 68,75 & 31,25 & 0,00 & 0,00 & 0,57 \\
Alemania & 0,00 & 11,90 & 66,67 & 9,52 & 11,90 & 0,48 \\
España & 1,79 & 53,57 & 30,36 & 0,00 & 14,29 & 0,40 \\
Francia & 4,40 & 56,04 & 25,27 & 5,49 & 8,79 & 0,39 \\
Gran Bretaña & 3,55 & 13,02 & 60,36 & 7,10 & 15,98 & 0,41 \\
Irlanda & 7,69 & 3,85 & 76,92 & 3,85 & 7,69 & 0,61 \\
Italia & 0,00 & 41,38 & 27,59 & 3,45 & 27,59 & 0,32 \\
Holanda & 1,67 & 21,67 & 45,00 & 1,67 & 30,00 & 0,34 \\
Total Global & 2,85 & 32,03 & 44,66 & 4,98 & 15,48 & 0,33 \\
& & & & & & \\
\hline
\end{tabular}

Fuente: EPO (2003) y elaboración propia.

Las diferencias observadas entre países están fuertemente relacionadas con la configuración de sus Sistemas Nacionales de Innovación y con el tipo de relaciones entre agentes que se mantienen desde el pasado o que son potenciadas desde las políticas de innovación. El aumento de las relaciones UniversidadEmpresa es ya un hecho estilizado. Las empresas son el principal socio de las universidades con más de dos tercios de las asociaciones en 4 de los 9 países 
estudiados, adquiriendo un nivel de importancia similar al de los CPIs, socios tradicionales en las cooperaciones universitarias.

Los campos técnicos en los que las cooperaciones son más importantes son Química y Farmacia (41,9 por ciento), Salud y Deportes (17,8 por ciento) e Instrumentos (15,3 por ciento) (Tabla 10). Sin embargo, este patrón general se modifica de acuerdo con el agente con quien ser realiza la cooperación. En las cooperaciones con la Administración, Instrumentos comparte importancia con Electricidad y, Salud y Deportes comparte importancia con Separación y Mezclas, Alimentos y Tabaco y Ciencia Nuclear. En las realizadas con CPIs, Electricidad comparte importancia con Instrumentos por encima de Salud y Deportes. En las realizadas con Empresas se observa el patrón general, aunque se acentúa la importancia de las cooperaciones en Química y Farmacia. En las mantenidas con Inventores Independientes, se presenta más importante Salud y Deportes que Química y Farmacia. Y, finalmente, en las cooperaciones entre Universidades, se mantiene también el patrón general, aunque toma mayor peso específico el área de Salud y Deportes e Instrumentos sobre la que presenta el total general. La dispersión de las cooperaciones según el agente cooperante entre los 21 campos técnicos contemplados es bastante similar, apareciendo levemente más concentrada en el caso de las cooperaciones entre Universidades.

\section{Conclusión}

Este artículo tenía como objetivo evaluar la posible pérdida de la función pública desempeñada por las universidades como proveedoras y difusoras de un importante bien público: el conocimiento científico y técnico. Esta pérdida de su función tradicional podría deberse al nuevo modelo regulador, iniciado en los EEUU con el Acta Bayh Dole de inicios de los ochenta, que permitía a las universidades apropiarse de los resultados de sus esfuerzos investigadores.

El Acta Bayh Dole abrió el debate sobre las consecuencias (positivas y negativas) de un probable re-direccionamiento de la función pública de las universidades. $\mathrm{Al}$ mismo tiempo, diversos autores cuestionaron si el Acta no seria más una consecuencia que una causa de algunas transformaciones registradas en los Sistemas Nacionales de Innovación, concretamente, el fortalecimiento de las relaciones Universidad-Empresa, la necesidad de nuevas fuentes de 
TABLA 10

Cooperaciones universitarias europeas por agente cooperante y por campo técnico

\section{Administración CPI Empresas Inventores Universidades HHI}

\begin{tabular}{|c|c|c|c|c|c|}
\hline Agricultura & 0,0 & 3,3 & 2,4 & 0,0 & 2,5 \\
\hline Alimentos y Tabaco & 6,3 & 0,6 & 0,8 & 0,0 & 0,0 \\
\hline Artículos uso personal & 0,0 & 0,0 & 0,4 & 0,0 & 0,0 \\
\hline Salud y deporte & 6,3 & 13,8 & 16,3 & 35,7 & 27,5 \\
\hline Separación y Mezclas & 6,3 & 5,5 & 7,2 & 7,1 & 2,5 \\
\hline Conformación & 0,0 & 1,1 & 3,6 & 0,0 & 1,3 \\
\hline Impresión & 0,0 & 0,0 & 0,0 & 0,0 & 0,0 \\
\hline Transporte & 0,0 & 0,0 & 0,4 & 0,0 & 0,0 \\
\hline Química y Farmacia & 37,5 & 43,1 & 43,4 & 25,0 & 41,3 \\
\hline Metalurgia & 0,0 & 1,7 & 2,4 & 0,0 & 2,5 \\
\hline Textil y materiales flexibles & 0,0 & 0,0 & 1,2 & 0,0 & 0,0 \\
\hline Papel & 0,0 & 0,6 & 0,0 & 3,6 & 0,0 \\
\hline Construcción & 0,0 & 0,0 & 1,6 & 7,1 & 0,0 \\
\hline Perforación y Minería & 0,0 & 0,0 & 0,0 & 0,0 & 0,0 \\
\hline Motores y Bombas & 0,0 & 0,6 & 1,2 & 0,0 & 0,0 \\
\hline Ingeniería & 0,0 & 0,0 & 0,4 & 0,0 & 0,0 \\
\hline Iluminación y Calefacción & 0,0 & 0,0 & 0,0 & 3,6 & 0,0 \\
\hline Armas y Explosivos & 0,0 & 0,0 & 0,0 & 0,0 & 0,0 \\
\hline Instrumentos & 18,8 & 14,9 & 13,9 & 17,9 & 18,8 \\
\hline Ciencia Nuclear & 6,3 & 0,0 & 0,0 & 0,0 & 0,0 \\
\hline Electricidad & 18,8 & 14,9 & 4,8 & 0,0 & 3,8 \\
\hline Total & 100,0 & 100,0 & 100,0 & 100,0 & 100,0 \\
\hline $\mathrm{HHI}$ & 0,23 & 0,25 & 0,25 & 0,23 & 0,28 \\
\hline
\end{tabular}

Fuente: EPO (2003) y elaboración propia. 
financiación de la investigación pública y el surgimiento de nuevas ciencias aplicadas a lo largo de los ochenta.

La discusión sobre la gravedad y la dimensión de tales consecuencias llevó al desarrollo de numerosos trabajos empíricos en los Estados Unidos que trataban de evidenciar, empíricamente, la corroboración de las hipótesis mantenidas en uno y otro sentido. Estos trabajos son relativamente escasos en Europa, aunque la polémica "publicar o patentar" ha sido objeto de profundo debate teórico durante los noventa de cara a posibles modificaciones de la regulación en la línea del Acta Bayh Dole.

En este sentido, este trabajo se propuso aportar alguna evidencia empírica que arrojase luz al debate en el caso europeo, es decir, sobre si existen modificaciones en el patrón de la actividad patentadora de las universidades en el periodo 1979-2002 y si éstas se vieron acompañadas de transformaciones como las relaciones Universidad-Empresa o de un fuerte desarrollo de nuevas disciplinas científicas de carácter aplicado. El análisis fue realizado a partir de la información contenida en la base de datos de la Oficina Europea de Patentes (EPO) entre diciembre de 1978 y diciembre de 2002. A partir de esta información, fue construida una muestra con las patentes depositadas por las universidades europeas en solitario y en cooperación para un total de 13 países europeos.

El análisis de los datos muestra que la actividad patentadora de las universidades europeas ha experimentado un fuerte crecimiento desde los años noventa y este crecimiento ha venido acompañado del fortalecimiento de las relaciones Universidad-Empresa y de la aparición de disciplinas como Ciencias de la salud y Microelectrónica, ambas de fuerte carácter aplicado.

Desde un punto de vista teórico, estas tendencias cuestionan la función pública como productora, formadora y difusora de conocimiento científico y técnico cuyo carácter es eminentemente público. Sin embargo, y como fue observado para el caso americano, el estudio de la actividad patentadora de las universidades europeas no permite concluir con que las nuevas tendencias representen una pérdida de la función pública universitaria por tres razones: (i) porque las patentes universitarias son todavía muy escasas, representando un pequeñísimo porcentaje del total de patentes depositadas por cada país, lo que se traduce en una escasa aportación a la formación de competencias tecnológicas nacionales; (ii) porque las universidades continúan concentrando y especializando 
sus esfuerzos investigadores en las áreas técnicas más próximas al conocimiento científico; y (iii) porque no han abandonado las vías de difusión tradicionales a través de las cuales queda asegurada la divulgación y extensión del CPI producido.

Estos resultados no se deben traducir en despreocupación por parte de las Administraciones Públicas. Tanto la aparición del nuevo modelo neo-regulador como el fuerte crecimiento de la actividad patentadora por parte de las universidades no dejan de ser muy recientes y todavía es pronto para observar algunos de los efectos perversos previstos. En la medida en que nuevas formas de financiación de la I+D universitaria están surgiendo y mayores son las relaciones entre Universidad y Empresa, nuevas formas restrictivas a la difusión de conocimiento podrían aparecer teniendo, como consecuencia, algunos de los efectos perversos previstos.

\section{Referencias bibliograficas}

Azagra. J. M.; Izquierdo Faubel, L.; Jiménez Sáez, F.; Serra Sister, P., "Factores Determinantes de la Generación de Patentes Universitarias: el caso de la Universidad Politécnica de Valencia", in Documento ES.3.226, Instituto de Gestión de la Innovación y el Conocimiento (INGENIO), Valencia, 2001. Blumenthal, D.; Cluck, L.K.; Seashore, M.A.; Wise, D., "University-industry Research Relationships in Biotechnology: implication for the university" in Science, 232, 13, 1361-1366, 1986.

Cohen, W.M.; Florida, R.; Randazzese, L.; Walsh, J., "Industry and the Academy: uneasy partners in the cause of technological advance", in Noll, R. (org.), Challenges to research universities., Washington: Bookings Institute, cap.7, p.171-199, 1998.

European Patent Office, jan., 2003; "European Patent Bulletin Information, dez., 1978-dez.2002", em formato DVD.

Gibbons, M.; Johnston R., "The Roles of Science in Technological Innovation”. In Research Policy, 3, 220-242, 1974. 
Henderson, R.; Jaffe, A. B.; Trajtenberj, M., "Universities as a Source of Commercial technology: a detailed analysis of university patenting 1965-1988", in Review of Economics and Statistics, 80, 119-127, 1998.

Klevorick, A. K.; Levin, R.C.; Nelson, R.R.; Winter, S.G., "On the Sources and Significance of Interindustry Differences in Technological Opportunities", in Research Policy, 24, 185-205, 1995.

Kuckartz, M., "Commercial Explotation of Academic and Scientific Research Inventions - a new duty for patent information", in World Patent Information, 21, 27-29, 1999.

Lee, Y.S., “'Technology Transfer' and the Research University: as search for the boundaries of university-industry collaboration", in Research Policy, 25, 843863, 1996.

Mansfield, E., "Academic Research and Industrial Innovation", in Research Policy, 20, 1-12, 1991.

"Academic Research and Industrial Innovation: an update of empirical findings", in Research Policy, 26, 773-776, 1998.

Mansfield, E.; Lee, Y. S., "The Modern University: contributor to industrial innovation and recipient on industrial R\&D support" in Research Policy, 25, 1047-1058, 1996.

Mowery D. C.; Nelson R. R.; Sampat, B.N.; Ziedonis, A. A., "The Growth of Patenting an Licensing by U.S. Universities: an assessment of the effects of the Bayh-Dole act of 1980", in Research Policy, 30, 99-119, 2001.

Thursby, J.G.; Kemp S., "Growth and Productive Efficiency of University Intellectual Property Licensing”, in Research Policy, 31, 109-124, 2002. 